\title{
ENTREVISTA CON BELÉN GACHE
}

\author{
Everton Vinicius de Santa* \\ Isabela Melim Borges Sandoval ${ }^{* *}$
}

Hola, Belén. Nos gustaría agradecer esa gran oportunidad de diálogo sobre su trabajo, sobre la literatura experimental y la poesía electrónica. Para nosotros, del Texto Digital, y para nuestros lectores eso es de suma importancia.

Everton de Santa: Para empezar nuestra discusión, nos gustaría saber un poco más sobre su historia profesional, sobre su relación con todo este movimiento de los nuevos medios digitales y con la poesía conceptual.

Belén Gache: Con respecto a mi relación con los medios de escritura digital, en 1994 publiqué mi primera novela, Luna India, que fue editada por Planeta. Esa novela fue el primer texto que escribí en un ordenador, un Amiga 500, con un procesador de textos que se llamaba TextCraft. Como monitor, usaba el televisor de mi casa. Fue algo natural para mí, saltar de esa situación a experimentar con literatura y ordenadores, incorporando imágenes y audios. Ya en 1996, formamos junto a Gustavo Romano (que venía de las artes visuales), Jorge Haro (músico), Carlos Trilnik (videoartista) y yo (desde la literatura) el grupo Fin del Mundo, que fue verdaderamente pionero en producciones de arte para la red, ya que internet acababa de hacerse disponible a los usuarios. Esta plataforma permaneció activa más de diez años. En cierta forma, era divertido tratar de explicarle a la gente en esa época qué era eso de arte y poesía digital. Había mucho desconocimiento y también mucha fantasía al respecto, incluso en los medios académicos. Con respecto al conceptualismo, siempre fue para mí un marco de partida, desde la poesía pero incluso también desde la narrativa. Las ideas de metadiscurso, de contrainte, de reescritura, siempre han estado en la base de mis procesos creativos.

\footnotetext{
*Universidad Complutense de Madrid, Madrid, Espanha. Imeio: evertonvs9@gmail.com

** Universidade Federal de Santa Catarina, Florianópolis, Brasil. Imeio: isaballoons@hotmail.com
} 
Isabela Sandoval: Cuéntanos brevemente sobre la poesía conceptual, los movimientos que la influyeron y su actuación en este movimiento.

Belén: Yo no entiendo al conceptualismo como un movimiento sino más bien como una lógica. Poéticas tan diferentes como las de Raymond Roussel, Marcel Duchamp, William Burroughs, el Nouveau Roman, Art \& Language, el Oulipo, las reflexiones de filósofos del lenguaje como Ludwig Wittgenstein pero también como Michel Foucault o Jacques Derrida, se relacionan todas ellas con una lógica conceptual ya que promueven una revisión de la concepción metafísica de la manera en que la lengua se relaciona con el mundo, de la manera en que las palabras se relacionan con las cosas. En mi libro Escrituras Nómades, yo subrayo cómo, a lo largo de la historia, muchas propuestas poéticas se han resistido frente a una escritura, en términos derridarianos, fonocéntrica y logocéntrica. Allí trato ejemplos de literaturas que involucran la autorreferencialidad y los juegos formales del lenguaje, la incorporación de nociones como la de máquina y de factores como el azar los trabajos que intentan una pulverización el signo lingüístico al abrirlo hacia su materialidad tanto visual como sonora. Creo que todas estas poéticas influyeron definitoriamente en mis obras.

Everton: ¿Usted entiende la poesía conceptual como un posible efecto de los movimientos antes mencionados, o su naturaleza nos permite hablar de una autonomía estética?

Belén: Sí, definitivamente. Creo que es imposible aislar a un texto de sus intertextos.

Isabela: ¿De qué manera la poesía conceptual o la literatura experimental pueden o quieren entender el mundo, una vez que ellos admiten una manera diferente de comprenderlo?

Belén: La escritura y la lectura siempre han sido asociadas a la interpretación y el entendimiento del mundo. Desde la historia mítica se nos cuenta que la escritura china fue inventada por un sabio que observaba la huella de las gaviotas en la arena de la playa. Los pigmeos de Kalahari decían que el hombre occidental no sabía leer porque no podía interpretar las huellas que dejan los animales sobre la tierra. En occidente, ellos eran los analfabetos porque no entendían el sistema de signos. La poesía trabaja con las palabras y es desde el mismo lenguaje que el poeta debe deconstruir las formas hegemónicas de comprender el mundo, basadas en la repetición automática de memes, en los lugares comunes, las 
folksonomías, los falsos causalismos, y fomentar la distancia crítica. Las palabras no son las cosas. Los poetas debemos lograr que se dude del lenguaje. Desde la poesía conceptual y experimental, se trabaja con estrategias tales como por ejemplo, el détournement, el énfasis en la materialidad significante, el uso de la aleatoriedad, de la homofonía, etcétera. Como señalaba Jacques Derrida, los significantes no responden a una realidad objetiva que los precede sino que es su propia materialidad la que resiste e impone sus propios significados. Las escrituras y las lecturas diferentes dan lugar a mundos diferentes. Escribir y leer de otra manera llevan a entender el mundo de otra manera. Numerosas poéticas han buscado deconstruir las formas canónicas de la escritura-lectura occidental a lo largo del siglo XX: las vanguardias históricas, las neovanguardias con los letristas, con las poéticas del acontecimiento (Fluxus, por ejemplo), el concretismo paulista, para quienes el espacio gráfico era valorado como agente estructural y las piezas eran concebidas como ideogramas. De este último movimiento surgen, a partir de los años 60, varias manifestaciones interesantísimas como el poema semiótico, el poema visivo, el poema proceso, en un espíritu de época teñido por las teorías de la comunicación, las teorías de la información y la semiótica. El advenimiento de los nuevos medios digitales, por su parte, anuló definitivamente la fronteras entre lo visual-verbal-auditivo dando lugar a prácticas en las que escribir-leer se presentaban como acciones radicalmente diferentes de las canónicas.

Everton: Teniendo en cuenta que se está utilizando la escritura digital, como el espacio-tiempo en que se experimenta la literatura $y$, por supuesto, que la reconfigura proponiendo diferentes poéticas, ¿cómo estuve y cómo está el escenario en Argentina o en España sobre esa "otra" forma de hacer literatura?

Belén: Es un momento de transición, o mismo de crisis, en el que asistimos a un cambio de paradigma que las formas convencionales no logran incorporar. Creo que, desde la escritura, debemos disfrutar este momento especialmente creativo en el que tantos modelos han tambaleado, incluso el mismo modelo de autor y el de signo escrito. Son muchos los escritores que enfrentan este desafío, en España, en Argentina, en todos lados. Año a año se multiplican las propuestas, teniendo en cuenta también que constantemente aparecen nuevos dispositivos. Desde la industria editorial, por su parte, no parecen salir del estado de shock.

Isabela: Cuéntanos sobre su trabajo o proyecto más experimental.

Belén: Para mí, cada texto es en sí un experimento. La misma idea de experimento me parece sumamente fértil. Hace un par de años dicté en México 
un seminario cuyo título era Poetas y antipoetas, científicos locos y máquinas disfuncionales que trabajaba con el paralelismo entre un científico loco y un poeta experimental. Recordemos que uno de los antecedentes directos de filosofías de vanguardia como el dadaísmo fue la ciencia patafísica, inventada por Alfred Jarry. La patafísica parodiaba la teoría y los métodos de la ciencia moderna y proponía enunciados muchas veces carentes de todo sentido. Según la propia definición de Jarry (y contrariamente a la física clásica, basada en una observación y pretendidamente objetiva de los fenómenos naturales), la patafísica se presentaba como la ciencia de las soluciones imaginarias, la ciencia de las excepciones.

Así como la ciencia experimental se ha caracterizado por no respetar modelos y ha intentado llevar más allá los límites de lo comúnmente aceptado, moviéndose en las fronteras entre lo posible y lo imposible, entre la razón y la locura, entre lo útil y lo inútil, entre la magia y la ciencia, entre la ciencia y el arte, de igual forma debe comportarse la poesia experimental con los limites del lenguaje.

Isabela: Sus últimos ensayos abordaran la idea de "liberarse de la cárcel del lenguaje", sin embargo, en el video Aurelia hay una lectora que se pierde a través de las calles, mientras está profundamente inmersa en la lectura de un libro. ¿Eso sería un oxímoron? ¿Cómo usted cree en un lenguaje abierta?

Belén: Posiblemente, Aurelia sea un paradigma de la necesidad del poeta de liberarse de la cárcel del lenguaje y fugar hacia el sin sentido, el sueño y la locura. Gérard de Nerval fue una de las principales figuras del movimiento romántico francés. Su poética tuvo una fuerte influencia sobre el simbolismo y el surrealismo. Perteneciente a grupos literarios extremos como El Club de los Haschischin o los Bouzingo, fue conocido por sus múltiples excentricidades entre las que se contaba, por ejemplo, el pasearse por los jardines del Palais-Royal con una langosta atada de una cinta, a manera de mascota. Su poema en prosa Aurélia da autobiográfica cuenta de su caída en la locura. En él, descubre el poder de los sueños y restablece su fe en el amor al abandonar el mundo de la razón. Nerval se suicidó a los 47 años. Se ahorcó de una farola con una cuerda que él decía, había pertenecido a la Reina de Saba. En los bolsillos de su gabán encontraron unas hojas con el manuscrito de Aurélia, texto que se convirtió en su testamento espiritual. Allí, el poeta categoriza al sueño como un estado "supernatural". El texto comienza con esta frase: "El sueño es una Segunda Vida". Por eso realicé esta lectura, en la que mi avatar pasea a la deriva leyendo fragmentos del texto de Gérard de Nerval, en Second Life. 
Isabela: ¿Cuáles son los proyectos en que usted está trabajando ahora y que piensa sobre el futuro de la literatura frente a los medios digitales?

B.G: Más que en el futuro de la literatura referido a las nuevas maneras de escribir o de editar libros, creo que habría que encarar la pregunta en un sentido más amplio.

¿Qué va a ser, por ejemplo, de instituciones públicas como las bibliotecas cuando la tecnología digital permita acceder a los documentos sin salir de nuestras casas? ¿Qué va a ser de las universidades cuando no haya necesidad de desplazarse ni para los alumnos ni para los profesores? Pero principalmente, estas instituciones deberán replantearse su rol y determinar ¿cuáles son los textos que valdrá la pena conservar y cuáles no?, ¿qué pasará con los chats, con twitter, con FB? ¿Cómo se catalogarán? ¿Cómo se incorporaran el audio y la imagen en sociedades acostumbradas durante siglos a que la conservación y transmisión de la cultura se daba a partir del libro impreso? A partir de los nuevos medios tecnológicos y de las grabadoras de sonido, la conservación del pensamiento y la cultura hoy no pasa de forma exclusiva por los libros. ¿Quién dice incluso, como planteaba Friedrich Kittler, que a largo plazo la misma escritura se vea amenazada por dictáfonos automáticos? En este momento estoy, precisamente reflexionando sobre todos estos temas en un proyecto de literatura transmedia que se llama KublaiMoon Project y que incorpora un blog de narrativa en proceso en el que yo (o más bien, mi alterego o avatar literario) soy una bibliotecaria encargada de la Biblioteca de Poesía de Kublai Khan, en la luna. Llevar adelante esta Biblioteca parece conllevar toda clase de peligros que ocasionan una serie de enemigos metrofóbicos (la metrofobia es el miedo a la poesía) que habitan a lo largo y ancho del cosmos.

Entrevista concedida por imeio. Texto recebido em: 10/04/2014. 